\title{
O ANTIDIÁLOGO ENTRE A FORMAÇÃO TECNOCIENTÍFICA E A HUMANÍSTICA NA EDUCAÇÃO TECNOLÓGICA
}

\section{GISANDRO CUNHA ILHA}

\author{
Universidade Federal de Santa Maria \\ E-mail: ilha.educ@gmail.com
}

\section{CRISTIANE MUENCHEN}

\section{Universidade Federal de Santa Maria \\ E-mail: crismuenchen@yahoo.com.br}

\section{RESUMO :}

Neste artigo, a partir de uma entrevista semiestruturada com alguns docentes de um curso superior de tecnologia em gestão ambiental, emergiram três categorias que permitiram caracterizar o que se chamou de antidiálogo entre a formação tecnocientífica e a humanística na Educação Tecnológica. Utilizando-se a Análise Textual Discursiva como recurso metodológico, apoiando-se a análise na articulação dos referenciais Freire/CTS que, dentre outros propósitos, reivindicam a participação social nas questões que concernem aos rumos da sociedade, buscou-se problematizar a fala dos docentes em relação aos seus quefazeres. A análise de alguns fatores emergidos neste estudo permitiram caracterizar o antidiálogo, destacando-se: a assunção de serem cursos transitórios e de demanda específica - voltados à preparação de mão-de-obra - com reflexos na estrutura curricular dos mesmos, além da sua incipiente inserção na comunidade regional.

\section{PALAVRAS-CHAVE:}

tecnociência, humanidades, antidiálogo.

\section{ANTIDIALOG BETWEEN THE TECHNO-SCIENTIFIC EDUCATION AND THE HUMANISTIC TECHNOLOGICAL EDUCATION}

\section{ABSTRACT:}

On this paper, from a semi-structured interview with some professors from a graduation course on Public Environmental Management, three categories emerged which allowed to characterize what was called Antidialog between the Techno-scientific Education and the Humanistic Technological Education. Using the Discursive Text Analysis as a methodological resource, supporting the analysis in the articulation of the referential of Freire/STS which, among other purposes, claim the social engagement on the issues concerning the paths of the society, we sought to render problematic the speech of the professors in relation to their duties. The analysis of some elements egressed on this study allowed us to qualify the antidialog, highlighting: the assumption of being transitory courses and of specific demand - focused on the preparation of hand labor - reflecting on its curricular structure, in addition to its inclusion in the regional community. 


\section{DEE Debates \\ em Educação Científica e Tecnológica \\ ISSN - 2236-2150 (Eletrônica)}

\section{KEYWORDS:}

technoscience, humanities, antidialog.

\section{INTRODUÇÃO}

Com raízes em contextos que vinculavam a educação profissional unicamente à formação de mão-de-obra, reservando esta às classes menos favorecidas, onde o desenvolvimento intelectual era visto como desnecessário àqueles que desempenhavam atividades braçais (BRASIL, PARECER CNE/CEB № 16/99), a educação para o trabalho de outrora se constituiu numa espécie de antecessora da educação tecnológica nos moldes vistos nos dias atuais.

Assim, de acordo com o exposto no relatório do Parecer CNE/CES № 436/2001, que trata dos Cursos Superiores de Tecnologia - Formação de Tecnólogos, até a década de 80, a formação profissional limitava-se ao treinamento para a produção em série e padronizada.

Já em meados da década de 1990 do século passado com a vigência da Lei 9394/96 - Lei de Diretrizes e Bases da Educação Nacional - que, dentre outras disposições, prevê, em seu artigo 40 que a educação profissional será desenvolvida em articulação com o ensino regular ou por diferentes estratégias de educação continuada, em instituições especializadas ou no ambiente de trabalho, começou-se a vislumbrar, pelo menos no papel, um novo cenário para a educação tecnológica no Brasil. Aliado a este fato, ainda, segundo o Parecer CNE/CES № 436/2001, posteriormente, um novo cenário econômico e produtivo se estabeleceu com o desenvolvimento e emprego de tecnologias complexas agregadas à produção e à prestação de serviços pela crescente internacionalização das relações econômicas.

Ainda neste contexto recente de expansão da educação tecnológica no Brasil o REUNI (Programa de Apoio a Planos de Reestruturação e Expansão das Universidades 
Federais) - com o objetivo de reduzir as taxas de evasão, aumentar o quantitativo de vagas ofertadas nas Instituições de Ensino Superior (IES), revisar a estrutura acadêmica com a reorganização dos cursos de graduação, buscando uma atualização das metodologias de ensino-aprendizagem, aliado a uma diversificação das modalidades de graduação e políticas de ampliação de assistência estudantil (BRASIL, DECRETO № 6.096, DE 24 DE ABRIL DE 2007, ART. 2º) - veio contribuir sobremaneira para a expansão da oferta dos cursos superiores de tecnologia no Brasil.

A partir de então, como política de governo e, de certa forma como resposta às demandas advindas de cenários externos, mas, principalmente, devido à escassez de "mão-de-obra" qualificada no país, a educação tecnológica de nível superior teve um crescimento no quantitativo de vagas ofertadas e no número de cursos abertos bastante expressivo.

Foi, então, a partir deste contexto histórico de expansão e consolidação da educação tecnológica no Brasil que se buscou, no presente estudo, um olhar para o processo formativo do tecnólogo numa perspectiva de formação geral, a partir das possíveis relações entre formação tecnocientífica e formação humanística, sustentado na articulação dos referenciais freireanos com os do Movimento CTS (Ciência,Tecnologia e Sociedade), notadamente os do PLACTS (Pensamento LatinoAmericano em Ciência,Tecnologia e Sociedade).

Segundo Auler (2002), a aproximação entre os pressupostos freireanos e a abordagem CTS também está no fato de ambas reivindicarem a participação social nas questões que concernem aos rumos da sociedade. Para isto, construir uma cultura de participação - considerando a história, a cultura e a situação socioeconômica - olhando-se para o contexto específico dos países da América Latina (AULER, 2011) através, ou a partir, de uma educação que contribua para a 
democratização dos processos decisórios constitui-se em alternativa ao modelo de não participação.

Como produtos sociais, ciência e tecnologia (embora haja quem defenda o contrário) estão carregadas de valores. Torna-se, portanto, necessário o desvelamento de uma série de questões envolvidas na sua gênese. Assim,

a conscientização implica, pois, que ultrapassemos a esfera espontânea de apreensão da realidade, para chegarmos a uma esfera crítica na qual a realidade se dá como objeto cognoscível e na qual o homem assume uma posição epistemológica (FREIRE, 2006, p.30, grifos nossos).

Sendo assim, a problematização - no sentido freireano do termo - que, conforme Muenchen (2010) não pode ser confundida com a simples pergunta, tendo a problematização como características para esta autora, dentre outras:

implicar em diálogo; existir, de fato, um problema a ser resolvido; ter como perspectiva a mudança, a transformação (grifo nosso); provocar o querer conhecer; propiciar uma leitura crítica do mundo; estimular a construção coletiva do conhecimento; relacionar explicitamente a realidade vivida pelo educando [...] (MUENCHEN, 2010, p. 161-162, adaptado).

pode constituir-se em um ponto de partida bastante viável na construção de um caminho autônomo para a formação de profissionais verdadeiramente livres, independentes e conscientes de suas decisões e atitudes, estruturando, desta forma, as bases de uma participação verdadeiramente efetiva dos cidadãos nas decisões concernentes não só à ciência e à tecnologia como, de resto, às demais áreas do conhecimento humano.

Neste processo de formação do cidadão participativo e consciente acredita-se ter o diálogo função estruturante. Ou se tem o diálogo, ou não. Parece não coexistirem em igualdade de condições em um mesmo locus, com as mesmas 
pessoas, num momento histórico determinado, o diálogo e o antidiálogo, até porque são antagônicos. E neste antagonismo um anularia o outro. Não se tem meio termo.

Mas o que é o diálogo, mesmo? Sinteticamente falando, apoiado mais uma vez em Freire (2012, p. 85): o diálogo é este encontro dos homens, mediatizados pelo mundo, para pronunciá-lo, não se esgotando, portanto, na relação eu-tu.

Para situar a discussão proposta neste estudo, destacam-se as características da teoria da ação antidialógica e da teoria da ação dialógica, na visão de Paulo Freire (2012).

Sendo assim, são características da ação antidialógica: a conquista; o dividir para manter a opressão; a manipulação e a invasão cultural. Já a ação dialógica tem como características: a co-laboração (sic); a união; a organização e a síntese cultural (FREIRE, 2012, p. 144-198).

\section{METODOLOGIA}

No estudo apresentado neste artigo $^{1}$, a partir de uma entrevista ${ }^{2}$ semiestruturada realizada com cinco docentes ${ }^{3}$ do Curso Superior de Tecnologia em Gestão Ambiental (CSTGA) da Unidade Descentralizada de Educação Superior da Universidade Federal de Santa Maria em Silveira Martins ${ }^{4}$ (UDESSM) ${ }^{5}$, optou-se por:

\footnotetext{
${ }^{1}$ Os resultados trazidos neste artigo são parte das discussões apresentadas na dissertação de mestrado de llha (2014).

${ }^{2}$ No intuito de se manter o mais fiel possível à fala dos docentes, as transcrições trazidas neste estudo são aquelas da fala coloquial, tais quais como pronunciadas pelos entrevistados.

${ }^{3}$ Docente A: graduação em Engenharia Florestal, com mestrado e doutorado na área de Silvicultura; Docente B: graduação, mestrado e doutorado na área de Engenharia Agrícola; Docente C: graduação em Geografia, especialização em Educação Ambiental, mestrado em Geografia e doutorado em Desenvolvimento Rural; Docente D: graduação em Engenharia Florestal, mestrado em Biologia na área de Ecologia e doutorado em Engenharia Florestal; Docente E: graduação em Geografia, mestrado em Desenvolvimento Rural e doutorado em Agronegócio.

${ }^{4}$ Cidade situada na região central do estado do Rio Grande do Sul, conhecida como berço da colonização italiana na região denominada como Quarta Colônia Imperial de Imigração Italiana no Rio Grande do Sul.
} 
verificar se no cotidiano do curso analisado ocorre o diálogo entre a formação tecnocientífica e a humanística e analisar os fatores envolvidos.

Como metodologia de análise da entrevista semiestruturada utilizou-se a Análise Textual Discursiva (ATD), conforme Moraes e Galiazzi (2007).

Desta forma, a partir da desconstrução ou unitarização das respostas dadas pelos professores, procurou-se elementos que constituíssem suas unidades básicas. Após, já adentrando na segunda etapa do processo - a categorização - buscou-se reunir os elementos semelhantes, independentemente do "lugar" que ocupavam naquelas respostas fornecidas na entrevista. Assim, neste processo de desconstrução/reconstrução, emergiram as categorias que em diálogo com o referencial teórico balizador deste estudo possibilitaram as discussões apresentadas na sequência deste trabalho.

A seguir, apresentam-se as questões que compuseram a entrevista semiestruturada realizada com os docentes:

1. Qual a sua área de formação?

1.1. Há quanto tempo o(a) senhor(a) é docente do curso?

2. Como o(a) senhor(a) analisa (em relação aos objetivos/relevância) a educação tecnológica no contexto atual do país?

\footnotetext{
${ }^{5}$ A UDESSM foi criada pela Resolução 028/08 da Universidade Federal de Santa Maria (UFSM) de 01/12/2008, de acordo com o decreto no 6.096, de 24 de abril de 2007 que instituiu o Programa de Apoio a Planos de Reestruturação e Expansão das Universidades Federais - REUNI, com início de suas atividades letivas no segundo semestre de 2009. Em setembro de 2016, de acordo com a Resolução N. 033/2016 da UFSM, o CSTGA foi transferido para a estrutura organizacional do Colégio Politécnico da UFSM, campus sede, na cidade de Santa Maria/RS.
} 


\section{DEDebates

3. A partir destas considerações, para o(a) senhor(a), qual a inserção do CSTGA na comunidade regional?

4. No PPC é apontada uma série de fatores que justificam um "indice socioeconômico de renda abaixo da média do estado" (nesta região). Ainda, segundo o PPC, um dos objetivos do curso é ajudar a superar esta condição. Sendo assim, na sua opinião, qual a relação entre educação e desenvolvimento, a partir da realidade do CSTGA?

5. O tema gerador do conhecimento nesta Unidade Descentralizada é o "desenvolvimento sustentável". $O(A)$ senhor(a) saberia explicar como se chegou a este tema?

5.1. O tema gerador, na sua percepção, é vivenciado no cotidiano do curso? Poderia dar exemplos?

6. O(A) senhor(a) participou da construção/elaboração do atual PPC do CSTGA?

6.1. Em caso positivo, poderia comentar, brevemente, possíveis situações que o(a) senhor(a) julga relevantes, ocorridas durante este processo?

7. Várias foram as razões para as mudanças ocorridas no Projeto do Curso, dentre algumas das citadas textualmente: "a constituição do quadro docente" (no início das atividades do curso o corpo docente ainda não estava completo); o fato de "os professores encontrarem dificuldades em executar os projetos"; "a falta de detalhamento na construção curricular, tendo como consequência observada a sobreposição de componentes curriculares"; "as disciplinas aplicadas, específicas do curso, não estavam suficientemente contempladas no currículo do curso"; "a presença de grande quantidade de carga horária dispensada aos Seminários Articuladores e Atividades Complementares de Graduação eram os maiores questionamentos, tanto por docentes quanto por discentes".

Então, pergunta-se: 
7.1. Como o(a) senhor(a) vê, no cotidiano do curso, estas mudanças?

7.2. O(a) senhor(a) concorda com estes argumentos que estão no Projeto Pedagógico do Curso justificando a sua alteração?

7.3. Como fica, na prática, neste novo PPC, o trabalho a partir de um tema gerador do conhecimento?

8. Como o(a) senhor(a) vê, no CSTGA, a integração - na prática - entre as disciplinas ou mesmo entre as áreas que compõem a grade curricular do curso?

9. Em questionário realizado com alguns alunos do CSTGA pode-se verificar, a partir de suas respostas, uma espécie de paradoxo no que concerne ao entendimento destes alunos sobre as relações da tecnociência com a sociedade, apenas para citar um exemplo.

A partir disto, pergunta-se: Questões de caráter mais amplo (político, social, epistemológico,...), como possíveis modelos de desenvolvimento, por exemplo, costumam entrar na pauta das discussões em aula? Na sua opinião, estas discussões são (seriam) relevantes à formação do tecnólogo? Por quê?

10. Na sua opinião, é possivel/viável articular formação científica e humanistica na educação tecnológica?

10.1. Em caso positivo, qual a relevância?

10.2. Quais as possiveis dificuldades ou impedimentos? 


\section{DEDebates \\ em Educação Científica e Tecnológica \\ ISSN - 2236-2150 (Eletrônica)}

\section{RESULTADOS}

Como resultado do estudo (que deu origem à dissertação de mestrado anteriormente aludida), a partir da ATD, chegou-se a oito categorias finais. Duas emergidas da análise do novo Projeto Pedagógico do Curso (PPC), três de um questionário aplicado aos alunos do CSTGA e mais três de uma entrevista semiestruturada realizada com alguns docentes deste curso.

No intuito de aprofundarem-se as discussões e por acreditar-se serem suficientemente representativas, focar-se-á o estudo aqui apresentado nas três últimas categorias, derivadas da entrevista com os docentes do CSTGA.

Antes, é preciso chamar atenção para dois fatores importantes. O primeiro deles é que o curso objeto desta análise estava alocado em um campus descentralizado, relativamente novo e, na época deste estudo, ainda em estruturação. O segundo, é que o curso houvera passado, recentemente, por uma reformulação de seu Projeto Pedagógico.

O PPC vigente à época (o novo PPC) estava estruturado em torno de uma grade de disciplinas distribuídas nos três eixos de formação do curso (Eixo de Formação Geral, Eixo de Gestão e Eixo de Formação Específica) com destaque para a instituição de pré-requisitos, até então inexistentes na antiga grade do CSTGA.

Este novo PPC foi fruto de uma alteração promovida no projeto original do curso (o antigo PPC) que estava baseado na Metodologia de Projetos e estruturado a partir dos chamados Seminários Articuladores de Módulo.

Dentre as razões textualmente citadas para a mudança do PPC, destacavamse: a constituição do quadro docente (no início das atividades do curso o corpo docente ainda não estava completo); o fato de os professores encontrarem dificuldades em executar os projetos (no antigo PPC); a falta de detalhamento na 
construção curricular, tendo como consequência observada a sobreposição de componentes curriculares; as disciplinas aplicadas, especificas do curso, não estavam suficientemente contempladas no antigo currículo do curso.

Feitas estas considerações, apresenta-se e discute-se, a seguir, as categorias emergidas das entrevistas com os docentes.

Categoria 1: Os Cursos Superiores de Tecnologia são para Suprir uma Demanda do Mercado de Trabalho

O título desta categoria é, sem dúvida, a característica mais marcante no contexto de todas as respostas de todos os entrevistados.

Para ilustrar, a seguir, reproduzem-se alguns trechos das falas dos docentes ao referirem-se aos objetivos e à relevância da educação tecnológica no contexto atual do país:

Quadro 1: Fala de professores sobre relevância da educação tecnológica. Fonte: Dados da Pesquisa.

Professor B - O próprio nome tecnológico já diz: atender a demanda, acabou a demanda fecha. Éo que está acontecendo com os nossos, acabou a demanda e agora são fechados.

Professora D - A educação tecnológica, ela vem pra atender um mercado né, mercado de trabalho direto, então quem forma na educação tecnológica sai da graduação para o trabalho.

Professora C -Olha, a educação tecnológica, a concepção dela se dá pensando em suprir demanda de mercado de trabalho, tanto que ele é um curso que pode ser aberto e quando acaba a demanda ele pode ser fechado [...] mas, para quem quer o mercado de trabalho, o tecnológico ele é mais rápido, é mais eficiente, as disciplinas são mais focadas.

Convém ressaltar que se observa na legislação que dispõe sobre o tema uma clara tendência em valorizar a articulação entre a formação tecnológica específica com uma formação de caráter mais geral e humanístico, onde:

a organização curricular compreenderá as competências profissionais tecnológicas, gerais e específicas, incluindo os fundamentos científicos e humanísticos necessários ao desempenho profissional do graduado em 
tecnologia (BRASIL, RESOLUÇÃO CNE/CP № 03/2002, ART. 6ㅇ, § 1으, grifo nosso).

Sendo assim, ao assumir-se uma perspectiva de educação geral, corroborando o que está escrito nos documentos oficiais, os currículos dos cursos superiores de tecnologia poderiam abrir espaço para uma maior inserção de aspectos humanísticos. E isto não significa que a formação tecnológica deva ser preterida, mas sim articulada e, talvez, aproximada dos verdadeiros anseios e necessidades da grande maioria das pessoas. Assim,

nesta [nova] estruturação, a hegemonia da cultura científica, base dos currículos profissionalizantes que focam apenas a especialização, [dividiria] espaço com outras formas de culturas entendidas hoje como tão importantes como aquela. Ao invés de domínio, [teríamos] diálogo e complementação entre as culturas e entre as áreas do conhecimento (PEREIRA, 2010, p. 9).

Todavia, na realidade do CSTGA, o foco na gestão e a questão de formar o profissional para o mercado de trabalho estavam tão presentes no discurso dos professores entrevistados que parecia ser visto pelo corpo docente, com certa naturalização, a influência que o conselho regulamentador da profissão de Tecnólogo em Gestão Ambiental, no caso, o Conselho Regional de Engenharia e Agronomia (CREA), tinha sobre as diretrizes curriculares do curso, notadamente, sobre a grade de disciplinas.

Explicitamente e, convém ressaltar, espontaneamente - uma vez que, até então, esta questão não tinha sido levantada neste trabalho por não ter sido percebida nas análises anteriores - os docentes justificaram a estruturação de um novo PPC pelo fato de que: 
Quadro 2: Fala da Professora C, grifo nosso. Fonte: Dados da Pesquisa.

Professora C - Todas as disciplinas que são dadas no curso, os nomes das disciplinas, são áreas de habilitação que eles podem assinar. Então, a gente teve muito cuidado quando a gente refez de que os nomes das disciplinas fossem muito claras, porque são habilitações. Por exemplo, o Projeto Pedagógico antigo tinha um monte de SAM (Seminário Articulador de Módulo), isto não habilita nada o aluno. Pra um curso de tecnólogo, era uma coisa inconcebível, porque a proposta era trabalhar o estado crítico do aluno, enquanto que o tecnólogo tem outro foco, é o mercado.

Além da influência do conselho regulamentador da profissão, outra pressão externa sofrida no processo de construção e sedimentação da proposta pedagógica de um curso novo - que necessitava ser reconhecido - num campus novo, que precisava se autoafirmar - era o próprio processo de reconhecimento deste curso por parte do MEC.

Assim, na visão dos professores entrevistados, de acordo com alguns pareceristas encarregados do reconhecimento do CSTGA, a estruturação proposta no antigo PPC, com uma grade aberta, que procurava, via Seminários Articuladores de Módulo, amarrar os conhecimentos das distintas áreas abarcadas nos projetos, nem vislumbrava uma perspectiva de formação do tecnólogo nem de formação de um bacharel.

Era nítido, também, o desconforto manifestado no relato dos professores entrevistados em relação àquela proposta inicial do curso. Foram recorrentes, em suas respostas, três fatores principais para este desconforto: formação docente (de certa forma, implícito nas respostas); a duração do curso (na época deste estudo, o tempo médio para a integralização curricular do aluno era de dois anos e meio, o que, segundo os relatos, tornaria bastante difícil trabalhar-se a partir de uma proposta mais aberta tendo que, ainda, segundo os entrevistados, atender-se às especificidades exigidas) e a falta de foco da grade de disciplinas (atrelada, novamente, à questão da habilitação profissional). 
A partir deste somatório de fatores - conjugados ao perfil dos docentes entrevistados - a educação tecnológica era vista, no âmbito dos docentes do CSTGA, com foco no mercado, especializada e de formação rápida.

Categoria 2: Os Projetos de Extensão como Interface entre a Universidade (Educação) e a Comunidade (Desenvolvimento Regional)

A lógica de produção de conhecimento na Universidade, a partir do ensino e da pesquisa, tendo a extensão como ponto de contato com a comunidade, era vista pelos entrevistados como a ponte entre os projetos, muitas vezes nascidos no interior da academia, e a possível demanda da comunidade regional.

Demanda que no caso da área de Gestão Ambiental está muito vinculada a adequação dos sistemas produtivos - com a minimização dos impactos ambientais provenientes das atividades antrópicas - à legislação ambiental regulamentadora (de acordo com o PPC e confirmada na entrevista com os docentes). Demanda não nascida, ao que parece, dos anseios da comunidade local onde o CSTGA estava inserido.

Nos dias de hoje sabe-se que os Projetos Pedagógicos da maioria das Instituições de Ensino Superior (IES) estão estruturados em torno do tripé ensinopesquisa-extensão, que são a base de sua organização.

A percepção que se tem, embora os subsídios disponíveis nesta pesquisa não permitam afirmar categoricamente (seria necessária uma análise mais detalhada deste aspecto) é que, muitos dos projetos de extensão nascem como demanda acadêmica de pesquisa e, segundo alguns professores entrevistados, quando a comunidade regional (em suas diferentes esferas) é procurada (teria que se observar em que momento do processo ela é procurada; para exercer qual papel; averiguar-se por que a iniciativa não partira da própria comunidade; esclarecerem-se as 
verdadeiras intencionalidades, dentre outros questionamentos), o envolvimento, algumas vezes, não é o esperado. Assim, a partir da fala de uma professora:

\section{Quadro 3: Fala da Professora D. Fonte: Dados da Pesquisa.}

Professora D - Enquanto o professor ficar só dentro daqui da academia fazendo seus projetos internos e sem formar uma rede professor/universidade com a região, com os representantes da região, inserir seus projetos em cada setor público aqui da região, isso não vai acontecer. Eu vejo que é necessário ir atrás dos representantes dos órgãos públicos aqui da comunidade e começar a trabalhar juntos [...]. A extensão é básica né, é básica, pra isso eu acho que a extensão é o pilar principal pra isso acontecer [...] no caso, aqui, o professor, ele tem que desapegar da situação de que o externo vai vir aqui pedir auxílio, não é isso que acontece aqui, somos nós que temos que ir atrás deles. Não é assim que funciona, ninguém vai vir aqui bater na porta, é a gente que tem que ir e, se for, tem horrores de coisa acontecendo. Só que tem que ir atrás e eu vejo que aqui não acontece muito, sabe. Mas, a partir do momento que aconteça, poderia dar muito certo.

Como consequência disto se faz necessária também uma problematização sobre qual/o que é a "nossa" pesquisa. Proveniente de que contextos?

Ademais, esta realidade parece não ser uma particularidade do CSTGA da UFSM, mas, de uma maneira geral, da grande maioria dos projetos de pesquisa e extensão das universidades brasileiras. Reforçando esta constatação, de acordo com as palavras de Dagnino (2010):

ao contrário dos países centrais, a agenda de pesquisa brasileira é deslocada, não está focada na nossa realidade. É cientificista, no sentido de que crê que a ciência é a verdade codificada que está na natureza, e o papel da comunidade de pesquisa é o descobrimento dessa verdade. Dessa forma, essa agenda tende a ser conservadora e pouco relevante. [...] A ideia de extensão tem uma conotação muito significativa, porque não indica um questionamento junto à sociedade ou aos atores sociais no intuito de saber o que Ihes é considerado relevante, para que a comunidade de pesquisa, remunerada pela sociedade, redirecione suas atividades. Trata-se de uma extensão ofertista, pois sem que a sociedade tenha solicitado, a 
comunidade de pesquisa oferta o que the parece mais interessante $e$ conveniente (DAGNINO, 2010, p. 285).

Além desta questão da mais alta relevância, outro aspecto que não pode deixar de ser citado, pois esteve presente na fala dos docentes, é, ainda, uma espécie de "preconceito" que alguns agricultores têm em relação ao gestor ambiental, visto como alguém que surge para multar, para fiscalizar. E isto, sem dúvida, cria uma barreira que também tem reflexo na extensão, além de evidenciar um possível conflito de interesses.

Categoria 3: A Verticalização Pretensamente Integradora da Grade de Disciplinas do Curso

No novo PPC, a estruturação da grade de disciplinas do curso nos seus três eixos de formação e, principalmente, a instituição de pré-requisitos, transmitia a ideia para alguns dos professores entrevistados de haver uma maior integração entre as disciplinas e, até mesmo, entre as áreas que compunham a nova matriz curricular do CSTGA quando comparadas ao antigo PPC.

Inicialmente, este fato parecia constituir um paradoxo. Como uma grade estruturada em torno de disciplinas rigidamente dispostas em torno de uma organização curricular verticalizada e atrelada a pré-requisitos (novo PPC) poderia pressupor uma maior integração do que a outra (antigo PPC) estruturada em torno de Seminários Articuladores de Módulo, pautada na Metodologia de Projetos?

Assim, segundo os professores entrevistados, devido à falta de especificidade (principalmente da disciplina de Seminário Articulador de Módulo, que no antigo PPC procurava fazer a articulação das disciplinas a partir dos projetos propostos em cada eixo), além das questões de formação docente e aceitação discente, na prática, muito pouco se observava de resultados concretos. 
Optou-se, então, segundo quem assim o defendia, por uma estruturação mais rígida e, principalmente com especificidades mais bem delimitadas (até pelas razões já anteriormente discutidas), muito embora se tenha percebido nas falas daqueles docentes, a clareza da perda das interações horizontais ${ }^{6}$.

\section{Quadro 4: Fala do Professor E. Fonte: Dados da Pesquisa.}

Professor E - Então, o pré-requisito, que parece ser uma coisa dura num componente curricular duro, né, que ele obriga o aluno a fazer isso pra depois fazer aquilo, ele também diz que é nesse tema integração daquela disciplina com aquela outra disciplina. [...]. A questão do seminário, SAM, ele tentava fazer isso, tentava fazer horizontalmente isso, se forçava pra acontecer isso, hoje não, tá mais isolado. A tendência do conteúdo é ser perpassante mesmo, só que a tendência tem que ver como é que o professor trabalha ela, dum projeto pro outro, acredito que tem bem menos. $O$ professor que pegava o SAM, ele tentava fazer uma costura, mal-feita ou bem-feita... Mas, realmente, com o PPC novo ele perde um pouco dessa horizontalidade, só que ele cria uma maior verticalidade, à medida que ele fica mais relacionado, o conteúdo fica dependente, porque não adianta você querer trabalhar uma questão mais horizontal se falta conhecimento que não tinha. Por exemplo, como é que vou trabalhar Geoprocessamento sem saber Matemática.

Ao serem questionados sobre a articulação entre as disciplinas ou mesmo entre as áreas do conhecimento, as respostas todas convergiam - embora, em alguns casos, implicitamente - para o fato de que, a partir do novo PPC (embora com uma grade mais "fechada") haveria, sim, a possibilidade de alguma articulação.

Como já mencionado, a lógica conteudista parecia pautar as justificativas daquele novo PPC.

A partir desta constatação, pode-se questionar o seguinte: qual a relação entre tema gerador (o tema gerador do conhecimento no CSTGA era o "desenvolvimento sustentável") e conteúdo no cotidiano do curso?

\footnotetext{
${ }^{6}$ No contexto deste estudo assume-se como interação horizontal aquela que se dá entre os componentes curriculares dentro de um mesmo semestre letivo, sem qualquer relação de hierarquia.
} 
Convém relembrar que uma organização curricular pautada em temas (pelo menos para quem vê o tema vinculado à realidade de onde ele deve ter emergido e não à lógica conteudista) deve estar estruturada de maneira que os conceitos científicos estejam subordinados ao tema e que aqueles (os conceitos, ou melhor, o conhecimento cientificamente estruturado) sejam chamados na tentativa de ajudar a esclarecer as demandas provenientes das problematizações oriundas da práxis (DELIZOICOV, ANGOTTI e PERNAMBUCO, 2011), a partir do tema gerador (FREIRE, 2012).

Ainda, a excessiva fragmentação da nova grade dava pistas de como isto vinha acontecendo no CSTGA, embora, ressalte-se, a sua articulação em torno dos três eixos estruturadores dos conteúdos, onde se buscava, pelo menos no papel, certa interligação destes "conteúdos".

Em contrapartida observa-se, diluído nas falas de alguns docentes, certo questionamento em relação àquela situação de fragmentação do conhecimento vinculado à área de formação de cada um e ministrado no interior de cada disciplina. Bastante representativo é o trecho a seguir, da professora D, ao falar das possíveis dificuldades ou impedimentos à articulação entre formação científica e humanística na educação tecnológica:

Quadro 5: Dificuldades na articulação entre formação humanística e científica. Fonte: Dados da Pesquisa.

Professora D - Não, só eu acho que não pode ser isolado, uma disciplina de educação em alguma coisa, não, isso tem que ter inserido em cada área, essa discussão tem que ser inserida nas áreas porque fica um apêndice e um apêndice que eles não têm afinidade nenhuma e, agora, se ela estiver diluída na forma como cada um vai trabalhar dentro da área, aí eu acho que faz todo sentido, bem diferente, só que daí você bate no perfil do docente [...]

O trabalho na perspectiva interdisciplinar, estruturado a partir do tema gerador, tendo os projetos de extensão como interface (não a única) com a 
comunidade na qual o curso está inserido: eis alguns dos elementos para a consecução de uma proposta de formação geral na perspectiva defendida neste estudo.

Desta forma, ao finalizar esta categoria, a percepção que se teve é de que se estruturou o novo PPC a partir de um olhar bastante disciplinar, possibilitando aos docentes uma espécie de "porto seguro" dentro da sua área específica de formação. Embora, conforme mostrado anteriormente, algumas percepções relativas a esta especificidade do currículo puderam, ainda que de forma tênue, ser observadas nas falas de alguns docentes.

\section{DISCUSSÕES FINAIS}

Como consequências ou implicações da antidialogicidade observada neste estudo, a realidade do CSTGA, em muitos aspectos, parecia aproximar-se de um modelo de educação que estava mais para o tradicional do que para o progressista.

A valorização extremada do conteúdo, justificada na especificidade do curso; a preparação para o mercado de trabalho, como se bastasse ser um 'bom profissional', para 'lograr êxito na vida'; a incipiente importância dada às questões humanísticas, com o pretexto de ser um curso de formação rápida: qual o reflexo? Posições que, no geral, pouco diferiam daquelas do chamado "senso comum".

Destarte, constatou-se ainda ser uma realidade distante (pelo menos no curso objeto desta análise) a formação do tecnólogo numa perspectiva de formação geral, embora o PPC antigo do CSTGA acenasse nesta direção.

Apesar de todos os contrapontos apresentados e discutidos até aqui, acreditase que os Cursos Superiores de Tecnologia, com foco na formação profissional, não precisam, ou melhor, não devem tê-la desvinculada de uma formação crítica e cidadã. 
A especificidade exigida em alguns contextos, não deveria ser entendida como sinônimo de acriticidade. As novas tecnologias e os avanços da ciência (não indistintamente e dependendo do contexto) poderiam, sim, estar a favor das causas sociais. Para isto acontecer, além da simples vontade, precisar-se-ia, dentre outras coisas - apoiando-se em Freire (2012) - conjugar ação e reflexão: a práxis, a partir da palavra verdadeira.

Contudo, acredita-se ter o currículo papel central neste processo de transformação. Uma alternativa, pressupõe-se, seja a assunção daquilo que Auler e Delizoicov (2001) classificaram como visão ampliada do currículo com ênfase em CTS, a partir da problematização dos denominados mitos, buscando-se a superação destas visões reducionistas, dentre elas: a) Superioridade do Modelo de Decisões Tecnocráticas: onde os rumos da sociedade deveriam estar a cargo de quem detém o conhecimento científico, os cientistas - pois somente através deste, a partir da observação rigorosa dos fatos e baseando-se no método científico - sem a interferência do restante da sociedade, com opiniões dúbias e providas de valores contestáveis, poder-se-ia chegar à verdade, já escrita na natureza; b) Perspectiva Salvacionista da CT: CT necessariamente conduzem ao progresso e CT sempre vêm, são criadas para solucionar problemas da humanidade, para tornar a vida mais fácil (p. 106); c) Determinismo Tecnológico: a tecnologia seria autônoma em seu desenvolvimento, estando o progresso social intimamente vinculado e dependente do progresso tecnológico (AULER, 2002).

Mitos presentes não só na sociedade, de uma maneira geral, como, conforme também constatado neste estudo, na academia.

A propagada especificidade dos cursos tecnológicos, como justificativa para o tangenciamento às questões sociais, poderia - a partir de uma proposta curricular baseada em CTS crítico, especificamente, a partir dos pressupostos do PLACTS - ser 
problematizada, neste caso, desconstruindo a visão dicotômica entre formação profissional e formação para a cidadania aqui apreendida.

Strieder (2012, p. 207) destaca que, para o desenvolvimento de compromisso social é necessário abordar a racionalidade científica, o desenvolvimento tecnológico e a participação social em seus níveis mais críticos. Ainda segundo a autora o que guia sua articulação e dá sentido às mesmas são os propósitos educacionais (Id. ibid., p. 206). E estes propósitos educacionais, corroborando com os pressupostos teóricos assumidos neste estudo, estão voltados para a articulação dos referenciais freireanos àqueles dos Estudos em Ciência, Tecnologia e Sociedade.

Assim, os pressupostos de um currículo baseado em CTS (visão ampliada) em articulação com o referencial freireano - que vê na superação da contradição educador-educando a exigência para uma educação problematizadora (FREIRE, 2012), onde quem forma se forma e re-forma (sic) ao formar e quem é formado forma-se e forma ao ser formado (FREIRE, 2009) - poderia, a partir disto, contribuir para a superação da visão reducionista que muitos dos docentes manifestaram em relação ao próprio trabalho com temas. Todavia, convém ressaltar, este processo não se desencadeará a partir do "vácuo". A formação para tal é imprescindível. Caso contrário, os resultados poderão continuar sendo muito semelhantes àqueles aqui constatados.

\section{REFERÊNCIAS}

AULER, D. Interações entre Ciência-Tecnologia-Sociedade no contexto da formação de professores de ciências. 2002. 258 f. Tese (Doutorado em Educação: ensino de Ciências Naturais) - Universidade Federal de Santa Catarina, Florianópolis, 2002. 
AULER, D. Novos caminhos para a educação CTS: ampliando a participação. In: AULER, D. (Org.); SANTOS, W. L. P. (Org.). CTS e educação científica: desafios, tendências e resultados de pesquisa. Brasília: UnB, 2011. p. 73 - 97.

AULER, D.; DELIZOICOV, D. Alfabetização científico-tecnológica para quê? Ensaio:

Pesquisa em Educação em Ciências, v. 3, n. 1, p. 105 - 115, 2001.

BRASIL. CONSELHO NACIONAL DE EDUCAÇÃO. Câmara de Educação Básica. Parecer CNE/CEB n. 16/99, de 05 de outubro de 1999. Trata das Diretrizes Curriculares Nacionais para a Educação Profissional de Nível Técnico. Educação profissional e tecnológica: legislação básica. 6. ed. Brasília: Secretaria de Educação Profissional e Tecnológica, 2005. p. $19-50$.

BRASIL. CONSELHO NACIONAL DE EDUCAÇÃO. Câmara de Educação Superior. Parecer CNE/CES n. 436/2001, de 05 de abril de 2001. Trata de Cursos Superiores de Tecnologia - Formação de Tecnólogos. Educação profissional e tecnológica:

legislação básica. 6. ed. Brasília: Secretaria de Educação Profissional e Tecnológica, 2005. p. $51-72$.

BRASIL. CONSELHO NACIONAL DE EDUCAÇÃO. Conselho Pleno. Resolução CNE/CP n. 03/2002, de 18 de dezembro de 2002. Institui as Diretrizes Curriculares Nacionais Gerais para a organização e o funcionamento dos cursos superiores de tecnologia. Educação profissional e tecnológica: legislação básica. 6. ed. Brasília: Secretaria de Educação Profissional e Tecnológica, 2005. p. 33-36.

BRASIL. Decreto n. 6.096, de 24 de abril de 2007. Institui o Programa de Apoio a Planos de Reestruturação e Expansão das Universidades Federais - REUNI. Diário Oficial da União, Brasília, DF, 25 abr. 2007. Seção 1, p. 7. Disponível em: <http://pesquisa.in.gov.br/imprensa/jsp/visualiza/index.jsp?data=25/04/2007\&jornal =1\&pagina=7\&totalArquivos=96>. Acesso em: 10 jan. 2014. 
BRASIL. Lei n. 9394, de 20 de dezembro de 1996. Estabelece as diretrizes e bases da educação nacional. Educação profissional e tecnológica: legislação básica. 6. ed. Brasília: Secretaria de Educação Profissional e Tecnológica, 2005. p. 11 - 36.

DAGNINO, R. (Org.). Estudos sociais da ciência e tecnologia \& política de ciência e tecnologia: abordagens alternativas para uma nova América Latina. 21. ed. Campina Grande: EDUEPB, 2010.

DELIZOICOV, D.; ANGOTTI, J. A.; PERNAMBUCO, M. M. Ensino de ciências: fundamentos e métodos. 4. ed. São Paulo: Cortez, 2011.

FREIRE, P. Conscientização: teoria e prática da libertação: uma introdução ao pensamento de Paulo Freire. São Paulo: Cortez \& Moraes, 2006.

FREIRE, P. Pedagogia da autonomia: saberes necessários à prática educativa. 40. reimpr. São Paulo: Paz e Terra, 2009.

FREIRE, P. Pedagogia do oprimido. Ed. especial. Rio de Janeiro: Nova Fronteira, 2012.

ILHA, G. C. O diálogo entre a formação tecnocientífica e a humanística na educação tecnológica: uma problematização a partir do estudo de caso do curso superior de tecnologia em gestão ambiental da UFSM. 2014. 86 f. Dissertação (Mestrado em Educação em Ciências) - Universidade Federal de Santa Maria, Santa Maria, 2014. MORAES, R.; GALIAZZI, M. C. Análise textual discursiva. Ijuí: Editora Unijuí, 2007. MUENCHEN, C. A disseminação dos três momentos pedagógicos: um estudo sobre práticas docentes na região de Santa Maria/RS. 2010. 273 f. Tese (Doutorado em Educação Científica e Tecnológica) - Universidade Federal de Santa Catarina, Florianópolis, 2010.

PEREIRA, E. M. A. (Org.). Universidade e currículo: perspectivas de educação geral. 1. ed. Campinas: Mercado de Letras, 2010. 
STRIEDER, R. B. Abordagens CTS na educação científica no Brasil: sentidos e perspectivas. 2012. 283 f. Tese (Doutorado em Ciências) - Universidade de São Paulo, São Paulo, 2012.

UNIVERSIDADE FEDERAL DE SANTA MARIA (UFSM). Projeto Pedagógico de Curso. Curso Superior de Tecnologia em Gestão Ambiental. Santa Maria: 2012.

UNIVERSIDADE FEDERAL DE SANTA MARIA (UFSM). Projeto Político-Pedagógico da Universidade Federal de Santa Maria. Conselho Superior de Ensino, Pesquisa e Extensão. Santa Maria, RS, 12 dez. 2000. Disponível em: <http://site.ufsm.br/arquivos/uploaded/arquivos/d8265cf3-7940-44a9-b025c51661536d87.pdf>. Acesso em: 10 maio 2014.

UNIVERSIDADE FEDERAL DE SANTA MARIA (UFSM). Resolução n. 028/08, de 1ำ de dezembro de 2008. Cria a Unidade Descentralizada de Educação Superior da Universidade Federal de Santa Maria, em Silveira Martins. Pró-Reitoria de Planejamento, Santa Maria, RS, 1ำ dez. 2008. Disponível em:<http://portal.ufsm.br/documentos/documentos/index.html?action=downloadA rquivo\&idArquivo=57>. Acesso em: 15 jan. 2014.

UNIVERSIDADE FEDERAL DE SANTA MARIA (UFSM). Resolução n. 033/2016, de 08 de setembro de 2016. Aprova a transferência do Curso Superior de Tecnologia Ambiental da Unidade Descentralizada de Ensino Superior de Silveira Martins UDESSM - para a estrutura organizacional do Colégio Politécnico da Universidade Federal de Santa Maria. Gabinete do Reitor, Santa Maria, RS, 08 set. 2016. Disponível em: <http://site.ufsm.br/arquivos/uploaded/uploads/c08f3832-2b69-47f8-a8782cc2bfc7f170.pdf>. Acesso em: 29 jan. 2018.

Recebido em: Setembro de 2016. Publicado em: Dezembro de 2017. 